\title{
Headspace solid-phase microextraction-gas chromatography-quadrupole mass spectrometric methodology for the establishment of the volatile composition of Passiflora fruit species
}

\author{
M. Pontes, J.C. Marques, J.S. Câmara* \\ Centro de Química da Madeira, Departamento de Química da Universidade da Madeira, Campus Universitário da Penteada. 9000-390 Funchal, Portugal
}

\section{A R T I C L E I N F O}

\section{Article history:}

Received 20 March 2009

Accepted 28 March 2009

Available online 7 April 2009

\section{Keywords:}

Passion fruit

Volatile compounds

Solid-phase microextraction

GC-qMS

\begin{abstract}
A B S T R A C T
Dynamic headspace solid-phase microextraction (HS-SPME) followed by thermal desorption gas chromatography-quadrupole mass spectrometry analysis (GC- ${ }_{\mathrm{q}} \mathrm{MS}$ ), was used to investigate the aroma profile of different species of passion fruit samples. The performance of five commercially available SPME fibres: $65 \mu \mathrm{m}$ polydimethylsiloxane/divinylbenzene, PDMS/DVB; $100 \mu \mathrm{m}$ polydimethylsiloxane, PDMS; $85 \mu \mathrm{m}$ polyacrylate, PA; 50/30 $\mu \mathrm{m}$ divinylbenzene/carboxen on polydimethylsiloxane, DVB/CAR/PDMS (StableFlex); and $75 \mu \mathrm{m}$ carboxen/polydimethylsiloxane, CAR/PDMS; was evaluated and compared. Several extraction times and temperature conditions were also tested to achieve optimum recovery. The SPME fibre coated with $65 \mu \mathrm{m}$ PDMS/DVB afforded the highest extraction efficiency, when the samples were extracted at $50{ }^{\circ} \mathrm{C}$ for 40 min with a constant stirring velocity of $750 \mathrm{rpm}$, after saturating the sample with $\mathrm{NaCl}(17 \%, \mathrm{w} / \mathrm{v}-0.2 \mathrm{~g})$. A comparison among different passion fruit species has been established in terms of qualitative and semiquantitative differences in volatile composition. By using the optimal extraction conditions and GC-qMS it was possible to tentatively identify seventy one different compounds in Passiflora species: 51 volatiles in Passiflora edulis Sims (purple passion fruit), 24 in P. edulis Sims f. flavicarpa (yellow passion fruit) and 21 compounds in Passiflora mollissima (banana passion fruit). It was found that the ethyl esters comprise the largest class of the passion fruit volatiles, including $82.8 \%$ in P. edulis variety, $77.4 \%$ in P. edulis Sims $\mathrm{f}$. flavicarpa variety and $39.9 \%$ in P. mollissima.

The semi-quantitative results were then submitted to principal component analysis (PCA) in order to establish relationships between the compounds and the different passion fruit species under investigation.
\end{abstract}

(c) 2009 Elsevier B.V. All rights reserved.

\section{Introduction}

The genus Passiflora comprising about 500 species is the largest of their family (Passifloraceae). This genus is common in places with tropical and warm climate, although it is much rarer in Asia, Australia, and Tropical Africa. From the several Passiflora species that grow in the tropics, the most widely found is Passiflora edulis Sims (passion fruit or purple granadilla) [1,2]. Madeira Island has a subtropical temperature, propitious to the development of some of these species, namely purple, yellow and, in little extension, banana passion fruit. The interest of researchers and producers by these species has been stimulated due to their good nutritional characteristics for industrialization since it presents a fresh pulp, soft peel, high sugar content and strong exotic flavor [3]. Because passion fruits are often inexpensive and extremely rich in vitamins, their popularity has increased, especially in Europe and in United States [3,4]. Volatiles directly affect the sensorial quality of fresh and processed fruit products, in which aroma is formed by a complex group of chemical substances (e.g.,

\footnotetext{
* Corresponding author. Tel.: +351 291 705112; fax: +351 291705149. E-mail address: jsc@uma.pt (J.S. Câmara).
}

aldehydes, alcohols, ketones, esters, lactones, terpenes). The concentration of these volatile compounds is generally low $(\mu \mathrm{g} / \mathrm{L})$ and can be affected by a number of agronomic (variety, climatological conditions, ripening stage) and technological (harvest, post-harvest treatments, storage and processing conditions) factors [5].

Passiflora fruits are normally used to produce juice and are one of the most nutritious fruit juices. It has been used as traditional folk medicines in Europe and North America owing to their sedative and antihypertensive properties, and a consistent number of these species are used as drugs in the pharmacopeias of several countries [2]. They are rich in carbohydrates, flavonoids, alkaloids, ascorbic acid, carotenoids, vitamins, minerals and terpenoid compounds. In addition, it is a good source of nicotinic acid, riboflavin and a fair source of mineral matter [6,7]. Carotenoids are widely regarded as effective quenchers of singlet oxygen, triplet oxygen and peroxyl radicals. Their polarity may influence antioxidant functioning since xanthophylls should function more efficiently against polar radicals $[1,8]$, have performed pharmacological studies on various species of passion fruits and they have noticed their significance in the treatment of central nervous system depressant effect.

Purple passion fruits ( $P$. edulis Sims) are round, purple externally when ripe and filled with orange pulp. The yellow passion fruits 

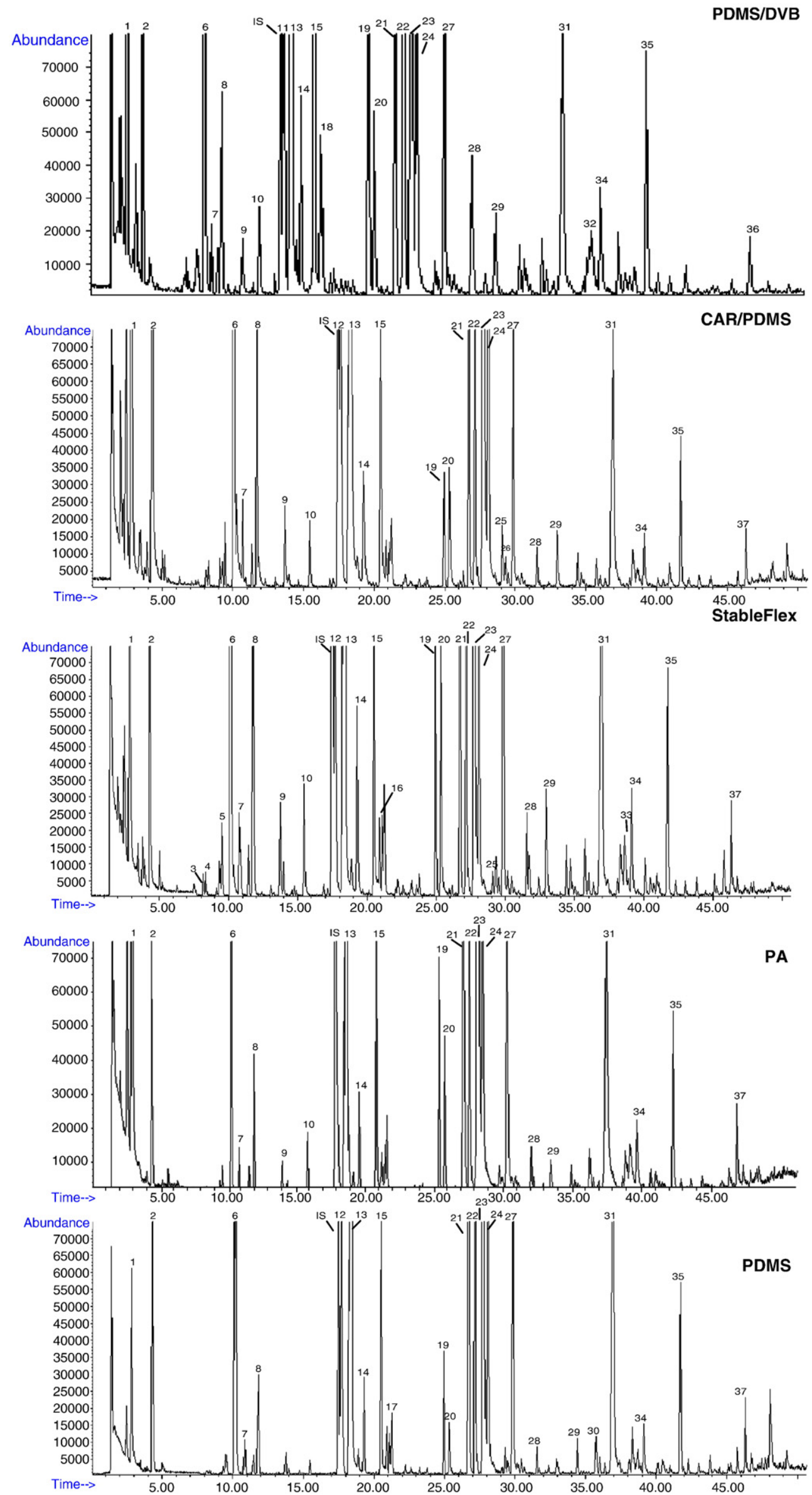
(P. edulis Sims f. flavicarpa) are bigger than the purple ones; they are yellow externally when ripe and filled with yellow pulp. Finally, banana passion fruits (Passiflora mollissima) have a long pendulum form, range from dark green to yellow-orange when fully ripe contain an orange-coulored pulp. This species is sweeter than the others and has less juice. All these species have black seeds. Purple passion fruit is the most used in the industry of fruit juices production and is known to be better for eating than yellow passion fruit because it is sweeter and not quite as acidic. The tolerance to heat or cold is similar to yellow passion fruit. Concerning yellow passion fruits, they have a "floral", "estery" aroma with an exotic tropical "sulphury" note. The main volatile compounds identified belong to the esters, namely methyl and ethyl esters [3,9]. Volatile esters are produced by virtually all soft fruit species during ripening. They play a role in the ripe fruit, serving both as "biological bribes" for the attraction of animals and as protectors against pathogens. Currently consumers are more interested in the provenance and authenticity of their food products. Fast identification of potential markers, suitable to qualitatively differentiate the food from various countries and regions, is a crucial requirement in regulations and for consumer confidence. Since the aroma is one of the most typical features of a food, the characterization of the aromatic profile can represent a useful tool to evaluate the organoleptic quality and it could be used to guarantee its authenticity.

Different techniques have been proposed for the extraction of the volatile compounds of foods. In general, volatile fractions have been recovered by conventional sampling methodologies such as steam distillation or solvent extraction. To overcome the problems associated with these techniques related with elevation costs, time-consumption, and the use of large volumes of organics solvents, the solid-phase microextraction (SPME) emerges as an attractive alternative. In addition, the SPME procedure will more closely reflect the true flavor profile of the fruit than those that might be generated by distillation and solvent extraction processes $[3,10]$. Since the first SPME fibres became commercially available, the technique of SPME has been more and more used and the fields of application have been continuously growing, including a wide range of food analysis, namely the volatile composition of wines [11-17] beers [18,19], whiskeys [20,21], honeys [22,23], sausages [24] and several kinds of fruits [25-29]. The technique gained growing acceptance and increasing use in routine laboratories and industrial applications.

In the present work, HS-SPME combined with GC-qMS, was developed and applied to evaluate the volatile composition profile of different passion fruit species: purple passion fruits ( $P$. edulis Sims); yellow passion fruits (P. edulis Sims f. flavicarpa) and banana passion fruits (P. mollissima). A preliminary screening of fibres of various polarities was carried out in order to select the best coating for the matrix. Comparison between the performance of five sorbent materials is given. Other conditions that might affect the SPME procedure, such as extraction time and temperature, were also investigated. To confirm the applicability of the SPME, a comparative study on the characteristic GCqMS volatile passion fruit profiles was performed. The possibility of differentiation from the investigated passion fruit was evaluated.

\section{Materials and methods}

\subsection{Chemicals and reagents}

All reagents used were of analytical quality: sodium chloride (99.5\%) used to obtain the adequate ionic strength was supplied by
Merck (Darmstadt, Germany) and water used was obtained by a Milli$Q$ purification system (Millipore). The $\mathrm{C}_{8}-\mathrm{C}_{20} \mathrm{n}$-alkanes series and the chemical standards were supplied by Sigma-Aldrich (Spain). The silica fibres and a SPME holder for manual sampling were obtained from Supelco (Bellefonte, PA, USA).

\subsection{Materials}

The SPME fibres and the fibre holders were purchased from Supelco (Bellefonte, PA, USA). Amber silanized glass vials $(4.0 \mathrm{~mL})$ were obtained from Agilent Technologies (Palo Alto, CA, USA). According to manufacturer's recommendation, the fibres were first conditioned in the gas chromatography (GC) injection port to remove fibre contaminants. Prior to extraction the fibre was, daily, inserted in the hot injection port for 6 min. A blank test was performed to check possible carry-over.

\subsection{Passion fruit samples}

The samples used in this work consisted of three passion fruit species: purple (MP), yellow (MY) and banana (MB) passion fruit, growing at Madeira Island (Portugal). All samples were obtained from local stores. Passion fruits were opened and the pulp was separated from the seeds to make juice. The juice was homogenised and stored at $-28{ }^{\circ} \mathrm{C}$ in glass bottles until analysis. All analysis, were carried out four times.

\subsection{SPME methodology}

HS-SPME is an equilibrium technique that requires a preceding optimization of the extraction parameters which might affect extraction efficiencies, in order to obtain high recoveries of volatiles. SPME parameters include fibre type, extraction temperature and extraction time.

\subsubsection{Selection of fibre coating}

Successful application of SPME depends primarily on the selection of a suitable fibre for a particular analysis. The efficiency of the analyte extraction and desorption from the fibre depends on the molecular weight, boiling point, vapour pressure of analytes and polarity and functional groups of the analytes and fibres. Five fibres were used for screening the passion fruits volatile profile: dimethylsiloxane layer (PDMS, $100 \mu \mathrm{m}$ ), recommended for nonpolar volatiles; polyacrylate (PA, $85 \mu \mathrm{m}$ ) with high selectivity for polar semivolatile compounds; divinylbenzene-carboxen-polydimethylsiloxane (DVB/CAR/PDMS (StableFlex), 50/30 $\mu \mathrm{m}$ ) recommended for flavours (volatiles and semivolatiles); carboxen-polydimethylsiloxane (CAR/PDMS, $75 \mu \mathrm{m}$ ); polydimethylsiloxane-divinylbenzene (PDMS/DVB, $65 \mu \mathrm{m}$ ). The coating of all fibres was $1 \mathrm{~cm}$ long. Purple passion fruit sample was selected as the matrix for comparison of the performance of all fibres. The fibre that presented the most complete profile of purple passion fruit volatile compounds was chosen to the study. The extraction was carried out for $20 \mathrm{~min}$ at $50{ }^{\circ} \mathrm{C}$ (controlled temperature) and each measurement was repeated four times. The PDMS/DVB fibre revealed to be the most suitable and was subsequently used in all further experiments.

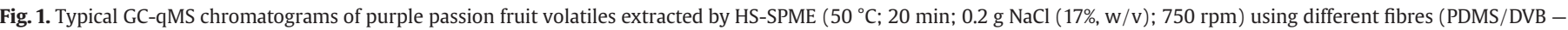

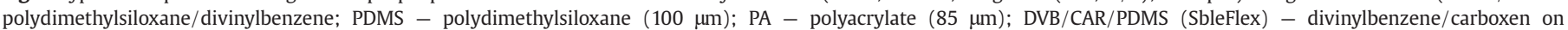

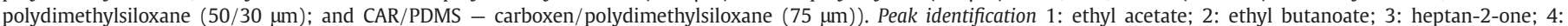

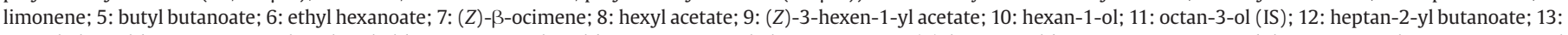

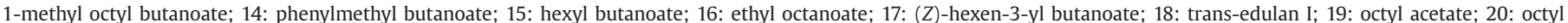

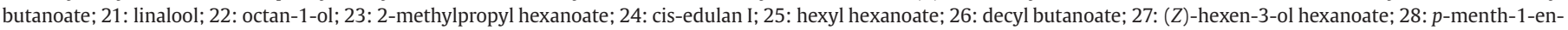

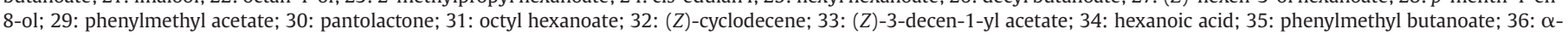
ionone; 37: phenylmethyl hexanoate.
} 
Table 1

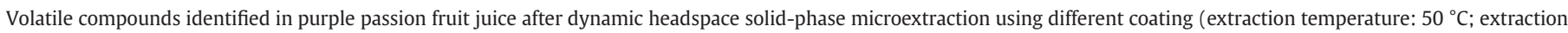
time: $20 \mathrm{~min}$; $750 \mathrm{rpm}$; 17\% (w/v) $\mathrm{NaCl}$ ).

\begin{tabular}{|c|c|c|c|c|c|c|}
\hline \multirow{2}{*}{ RT (min) } & \multirow{2}{*}{ Compounds } & \multicolumn{5}{|c|}{ SPME coatings } \\
\hline & & PDMS/DVB & CAR/PDMS & PDMS & Stableflex & $\overline{\mathrm{PA}}$ \\
\hline 2.539 & Ethyl acetate & $\mathrm{x}$ & $\mathrm{x}$ & - & $\mathrm{x}$ & - \\
\hline 3.670 & Methyl butanoate & $\mathrm{x}$ & $\mathrm{x}$ & - & - & - \\
\hline 4.039 & 2-methyl methylbutanoate & $\mathrm{x}$ & - & - & - & - \\
\hline 4.540 & Ethyl butanoate & $\mathrm{x}$ & $\mathrm{x}$ & $\mathrm{x}$ & $\mathrm{x}$ & $\mathrm{x}$ \\
\hline 5.294 & Butyl acetate & $\mathrm{x}$ & $\mathrm{x}$ & - & - & - \\
\hline 5.298 & Methylpropyl acetate & $\mathrm{x}$ & $\mathrm{x}$ & - & - & - \\
\hline 8.553 & Heptan-2-one & - & - & - & $\mathrm{x}$ & - \\
\hline 8.698 & Limonene & - & $\mathrm{x}$ & - & $\mathrm{x}$ & - \\
\hline 8.750 & Methyl hexanoate & $\mathrm{x}$ & - & - & - & - \\
\hline 9.756 & 1-methylbutyl butanoate & $\mathrm{x}$ & $\mathrm{x}$ & - & $\mathrm{x}$ & - \\
\hline 9.942 & Butyl butanoate & $\mathrm{x}$ & $\mathrm{x}$ & - & $\mathrm{x}$ & - \\
\hline 10.534 & Ethyl hexanoate & $\mathrm{x}$ & $\mathrm{x}$ & $\mathrm{x}$ & $\mathrm{x}$ & $\mathrm{x}$ \\
\hline 11.187 & $(Z)$ - $\beta$-ocimene & $\mathrm{x}$ & $\mathrm{x}$ & $\mathrm{x}$ & $\mathrm{x}$ & - \\
\hline 11.865 & 2-heptyl acetate & $\mathrm{x}$ & - & - & $\mathrm{x}$ & - \\
\hline 12.260 & Hexyl acetate & $\mathrm{x}$ & $\mathrm{x}$ & $\mathrm{x}$ & $\mathrm{x}$ & $\mathrm{x}$ \\
\hline 13.574 & 3-ethyl hexanoate & $\mathrm{x}$ & $\mathrm{x}$ & - & $\mathrm{x}$ & - \\
\hline 14.220 & (Z)-3-hexen-1-yl acetate & $\mathrm{x}$ & $\mathrm{x}$ & $\mathrm{x}$ & $\mathrm{x}$ & $\mathrm{x}$ \\
\hline 14.437 & Heptan-2-ol & $\mathrm{x}$ & - & - & $\mathrm{x}$ & - \\
\hline 15.287 & Hexyl propanoate & $\mathrm{x}$ & - & - & - & - \\
\hline 15.925 & Hexan-1-ol & $\mathrm{x}$ & $\mathrm{x}$ & - & $\mathrm{x}$ & $\mathrm{x}$ \\
\hline 17.362 & (Z)-3-hexen-1-ol & $\mathrm{x}$ & - & - & $\mathrm{x}$ & \\
\hline 17.614 & 2-heptyl butanoate & - & - & - & - & $\mathrm{x}$ \\
\hline 18.248 & 1-methylhexyl butanoate & $\mathrm{x}$ & $\mathrm{x}$ & $\mathrm{x}$ & $\mathrm{x}$ & - \\
\hline 18.350 & 2-methylbutyl hexanoate & $\mathrm{x}$ & - & - & - & - \\
\hline 18.780 & 1,1-dimethylpropyl hexanoate & - & - & $\mathrm{x}$ & $\mathrm{x}$ & - \\
\hline 18.827 & Butyl hexanoate & $\mathrm{x}$ & $\mathrm{x}$ & - & $\mathrm{x}$ & $\mathrm{x}$ \\
\hline 18.915 & Hexyl butanoate & $\mathrm{x}$ & $\mathrm{x}$ & $\mathrm{x}$ & $\mathrm{x}$ & $\mathrm{x}$ \\
\hline 19.490 & 3-methylhexyl butanoate & $\mathrm{x}$ & - & - & - & $\mathrm{x}$ \\
\hline 19.899 & Ethyl octanoate & $\mathrm{x}$ & $\mathrm{x}$ & $\mathrm{x}$ & $\mathrm{x}$ & $\mathrm{x}$ \\
\hline 21.144 & (Z)-3-hexenyl butanoate & $\mathrm{x}$ & $\mathrm{x}$ & $\mathrm{x}$ & $\mathrm{x}$ & $\mathrm{x}$ \\
\hline 21.582 & Trans-edulan i & $\mathrm{x}$ & $\mathrm{x}$ & $\mathrm{x}$ & $\mathrm{x}$ & $\mathrm{x}$ \\
\hline 21.672 & Octyl acetate & $\mathrm{x}$ & - & - & - & - \\
\hline 21.752 & Ethyl 4-octenoate & $\mathrm{x}$ & - & - & $\mathrm{x}$ & - \\
\hline 21.893 & Octyl butanoate & $\mathrm{x}$ & - & $\mathrm{x}$ & - & - \\
\hline 23.210 & 2-methylbutyl propanoate & - & $\mathrm{x}$ & - & $\mathrm{x}$ & - \\
\hline 23.719 & 3-cyclohexene-1-propanol & - & - & $\mathrm{x}$ & - & - \\
\hline 25.531 & Linalool & $\mathrm{x}$ & $\mathrm{x}$ & $\mathrm{x}$ & $\mathrm{x}$ & $\mathrm{x}$ \\
\hline 25.887 & Octan-1-ol & $\mathrm{x}$ & $\mathrm{x}$ & - & $\mathrm{x}$ & $\mathrm{x}$ \\
\hline 27.371 & 2-methylpropyl hexanoate & - & $\mathrm{x}$ & - & - & $\mathrm{x}$ \\
\hline 27.881 & Cis-edulan i & $\mathrm{x}$ & $\mathrm{x}$ & $\mathrm{x}$ & $\mathrm{x}$ & $\mathrm{x}$ \\
\hline 27.905 & 2-pentyl octanoate & - & $\mathrm{x}$ & $\mathrm{x}$ & $\mathrm{x}$ & - \\
\hline 28.420 & Hexyl hexanoate & $\mathrm{x}$ & - & $\mathrm{x}$ & $\mathrm{x}$ & $\mathrm{x}$ \\
\hline 28.767 & Decyl butanoate & $\mathrm{x}$ & $\mathrm{x}$ & $\mathrm{x}$ & $\mathrm{x}$ & $\mathrm{x}$ \\
\hline 29.080 & Ethyl decanoate & - & $\mathrm{x}$ & - & $\mathrm{x}$ & - \\
\hline 29.293 & 1-ethenyl hexyl butanoate & - & - & - & - & $\mathrm{x}$ \\
\hline 29.472 & (Z)-5-octen-1-ol & - & - & $\mathrm{x}$ & - & $\mathrm{x}$ \\
\hline 29.490 & 1,4-octadiene & - & - & - & $\mathrm{x}$ & - \\
\hline 29.502 & 2-methyl-bicyclo[4.1.0]heptane & - & $\mathrm{x}$ & - & - & - \\
\hline 29.983 & (E)-3-octen-1-yl acetate & $\mathrm{x}$ & $\mathrm{x}$ & $\mathrm{x}$ & $\mathrm{x}$ & - \\
\hline 30.532 & (Z)-3-hexenyl hexanoate & $\mathrm{x}$ & $\mathrm{x}$ & $\mathrm{x}$ & $\mathrm{x}$ & $\mathrm{x}$ \\
\hline 32.153 & P-menth-1-en-8-ol & $\mathrm{x}$ & $\mathrm{x}$ & - & $\mathrm{x}$ & - \\
\hline 33.689 & Phenylmethyl acetate & $\mathrm{x}$ & $\mathrm{x}$ & $\mathrm{x}$ & $\mathrm{x}$ & $\mathrm{x}$ \\
\hline 35.417 & 2-hydroxymethyl benzoate & $\mathrm{x}$ & - & - & $\mathrm{x}$ & - \\
\hline 35.735 & Pantolactone & - & - & $\mathrm{x}$ & - & - \\
\hline 37.543 & Hexyl hexanoate & $\mathrm{x}$ & - & - & - & - \\
\hline 37.585 & Octyl hexanoate & $\mathrm{x}$ & - & $\mathrm{x}$ & $\mathrm{x}$ & $\mathrm{x}$ \\
\hline 38.314 & 4-ethyl cyclohexene & - & $\mathrm{x}$ & - & - & $\mathrm{x}$ \\
\hline 38.320 & (Z)-3-decen-1-yl acetate & - & - & $\mathrm{x}$ & $\mathrm{x}$ & - \\
\hline 38.926 & Hexanoic acid & $\mathrm{x}$ & - & - & $\mathrm{x}$ & - \\
\hline 39.324 & Geranyl cetone & $\mathrm{x}$ & - & - & - & - \\
\hline 39.857 & Phenylmethyl butanoate & - & $\mathrm{x}$ & $\mathrm{x}$ & $\mathrm{x}$ & $\mathrm{x}$ \\
\hline 40.922 & 2-phenylethanol & - & $\mathrm{x}$ & - & - & - \\
\hline 41.152 & Linalyl acetate & $\mathrm{x}$ & - & - & - & - \\
\hline 42.459 & Dihydro- $\beta$-ionone & $\mathrm{x}$ & $\mathrm{x}$ & $\mathrm{x}$ & $\mathrm{x}$ & $\mathrm{x}$ \\
\hline 43.021 & 2-methyl-2-phenylethyl butanoate & $\mathrm{x}$ & $\mathrm{x}$ & $\mathrm{x}$ & $\mathrm{x}$ & - \\
\hline 45.740 & (Z)-cyclodecene & - & - & $\mathrm{x}$ & - & $\mathrm{x}$ \\
\hline 46.698 & Phenylmethyl hexanoate & $\mathrm{x}$ & $\mathrm{x}$ & $\mathrm{x}$ & $\mathrm{x}$ & $\mathrm{x}$ \\
\hline 46.948 & 3-phenylethyl propanoate & - & - & $\mathrm{x}$ & $\mathrm{x}$ & - \\
\hline 47.114 & 5-hydroxymethyl furfural & $\mathrm{x}$ & - & - & - & - \\
\hline 47.627 & Ethyl cinamate & $\mathrm{x}$ & - & - & - & - \\
\hline 49.385 & DDMP $^{\mathrm{a}}$ & $\mathrm{x}$ & - & - & - & - \\
\hline \multicolumn{2}{|c|}{ Total compounds per fibre } & 51 & 39 & 31 & 45 & 28 \\
\hline
\end{tabular}

-: Not detected.

a DDMP: 2,3-dihydro-3,5-dihydroxy-6-methyl-4(H)-pyran-4-one. 


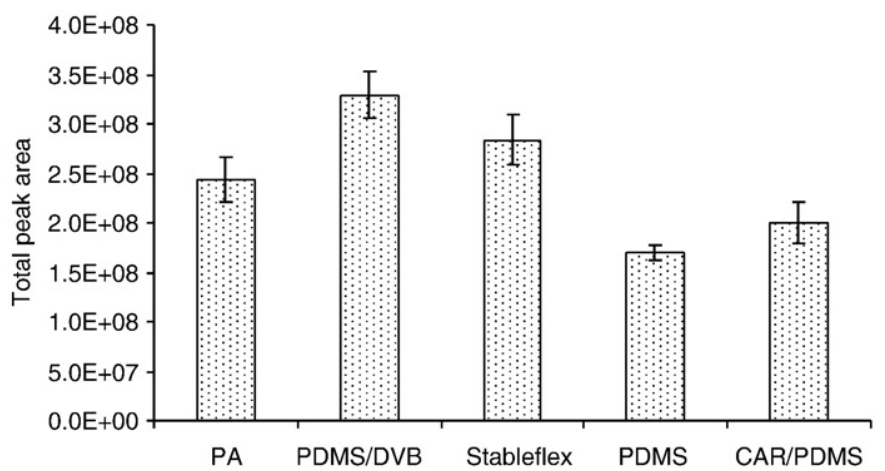

Fig. 2. Extraction efficiencies measured for different SPME coatings. Error bars represent standard error of the mean ( $n=4$ for each data point).

\subsubsection{Selection of extraction time and extraction temperature}

In order to obtain the maximum extraction yield for each volatile constituent, exposure times and temperatures were adjusted. With other conditions invariable, the extraction time profile was constructed at the extraction temperatures of $50{ }^{\circ} \mathrm{C}$ with $10,20,40$ and $60 \mathrm{~min}$ of the analytes isolation. An optimal extraction time of $40 \mathrm{~min}$ was selected. Keeping the extraction time constant, the extraction temperature was carried out from 40 to $80{ }^{\circ} \mathrm{C}$. Desorption time was 6 min and the temperature in the GC liner was $260{ }^{\circ} \mathrm{C}$.

\subsubsection{HS-SPME procedure}

The volatile compounds were monitored by sampling the headspace of the passion fruits by using the headspace SPME technique. For each extraction, an aliquot of $0.2 \mathrm{~mL}$ of juice sample diluted with $1 \mathrm{~mL}$ deionised water (Milli-Q), was introduced in a $2 \mathrm{~mL}$ glass vial hermetically sealed and equilibrated during $20 \mathrm{~min}$ in a thermostatic bath on a stirrer. The extractions were carried out without $\mathrm{pH}$ adjustment. The ionic strength was increased using $\mathrm{NaCl}(17 \%(\mathrm{w} / \mathrm{v})-0.2 \mathrm{~g})$, analytical grade) to improve the extraction efficiency by decreasing the solubility of hydrophilic compounds in the aqueous phase. The SPME fibre was then exposed to the headspace of the sample and kept for $20 \mathrm{~min}$ at $50{ }^{\circ} \mathrm{C}$. As stirring usually improves the extraction, because the static layer resistant to mass transfer is destroyed (facilitate mass transport between the bulk of the aqueous sample and the fibre), all the experiments were performed under constant stirring speed of $750 \mathrm{rpm}$.

After sampling, the SPME fibre was withdrawn into the needle, removed from the vial and inserted into the hot injector port $\left(260^{\circ} \mathrm{C}\right)$

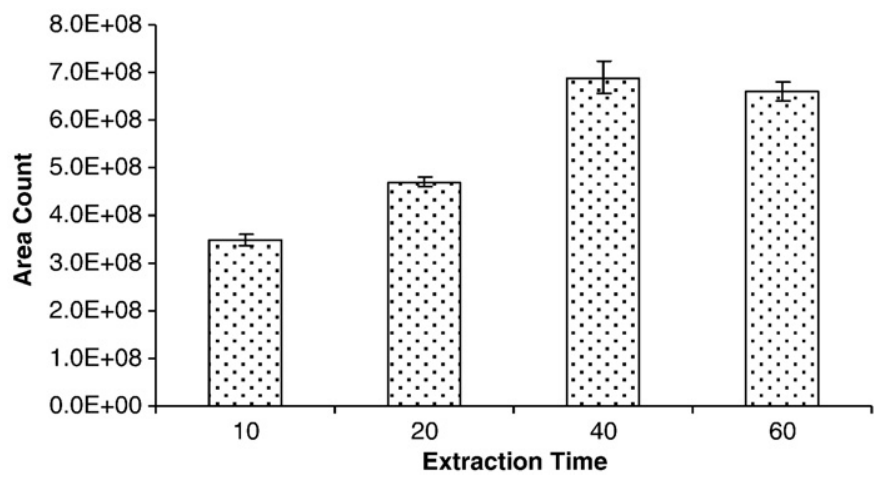

Fig. 4. Influence of extraction time on absorption of purple passion fruit flavour compounds during HS-SPME extraction using a PDMS/DVB fibre $\left(50{ }^{\circ} \mathrm{C}\right.$, with $0.2 \mathrm{~g}$ of $\mathrm{NaCl}(17 \%, \mathrm{w} / \mathrm{v}))$.

of the GC-qMS system for 6 min where the extracted analytes were thermally desorbed and transferred directly to the analytical column.

\subsection{Gas chromatography-quadrupole mass spectrometry analysis (GC-qMS)}

The volatiles extracted by dynamic HS-SPME from passion fruit samples, were separated and identified in an Agilent 6890N Network gas chromatograph system (Palo Alto, CA, USA) equipped with a $30 \mathrm{~m} \times 0.25 \mathrm{~mm}$ i.d., with a $0.25 \mu \mathrm{m}$ film thickness, BP-20 fused silica capillary column (polar) from Scientific Glass Engineering (Milton Keynes, UK), coupled to an Agilent 5975 quadrupole inert mass selective detector. Helium (Helium N60, Air Liquid, Portugal) was used as the carrier gas at a flow rate of about $1 \mathrm{~mL} / \mathrm{min}$ (column-head pressure: $13 \mathrm{psi}$ ). The liner injection port was lined with a $0.75 \mathrm{~mm}$ (I. D.) splitless glass liner. The injections were performed in the splitless mode. The initial oven temperature, $40^{\circ} \mathrm{C}$, was held for $1 \mathrm{~min}$ and then increased in two steps: $40^{\circ} \mathrm{C}$ to $150^{\circ} \mathrm{C}$, at $2.5^{\circ} \mathrm{C} / \mathrm{min}$ and 150 to $220^{\circ} \mathrm{C}$ at $15{ }^{\circ} \mathrm{C} / \mathrm{min}$. The manifold, GC-qMS interface and quadrupole temperatures were held at $180{ }^{\circ} \mathrm{C}, 220{ }^{\circ} \mathrm{C}$ and $180{ }^{\circ} \mathrm{C}$, respectively. The detection was performed by a 5975 mass spectrometer in the electronic impact mode (EI at $70 \mathrm{eV}$ ). The electron multiplier was set to the auto tune procedure. The mass acquisition range, made in a full scan mode, was $30-300 \mathrm{~m} / z ; 1.9$ spectra/s.

Volatile compounds were identified by comparing the MS fragmentation pattern with those of the pure standards and mass spectrum of the unknown peaks with those stored in the NIST05 library, retention times of the pure standards obtained under the same

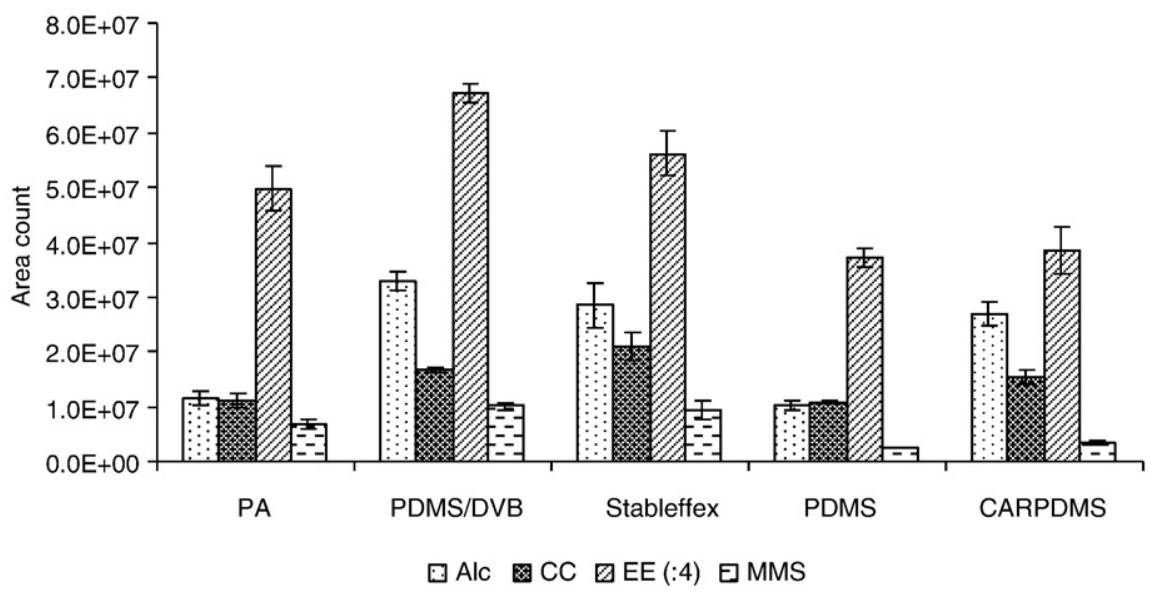

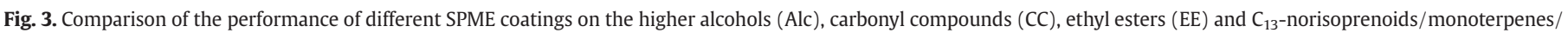
sesquiterpenes (NMS). 


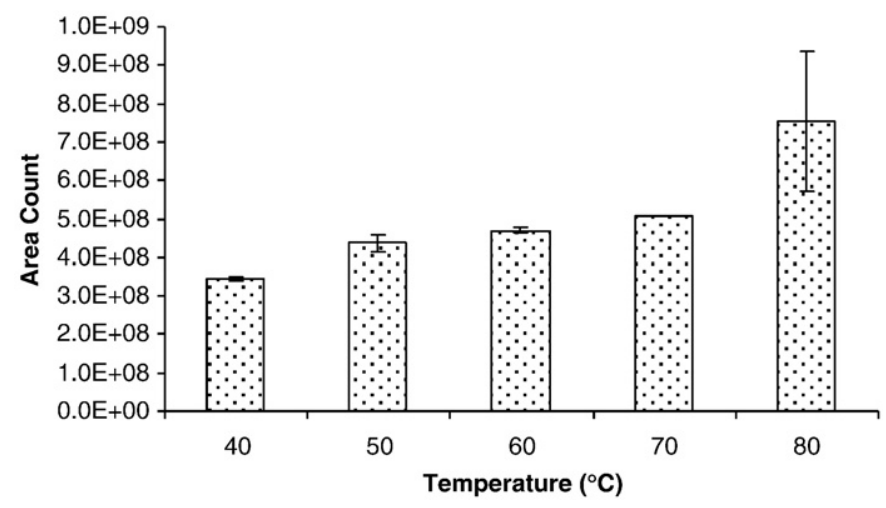

Fig. 5. Effect of extraction temperature on SPME of passion fruit volatile organic compounds with the PDMS/DVB fibre (extraction time: 20 min, headspace sampling with $17 \%(\mathrm{w} / \mathrm{v})$ of $\mathrm{NaCl})$.

conditions, and Kováts retention indices (KI). For the determination of the $\mathrm{KI} \mathrm{a} \mathrm{C}_{8}-\mathrm{C}_{20} \mathrm{n}$-alkanes series was used. The relative amounts of individual components are expressed as percent peak areas relative to the total peak area (Relative Peak Area, RPA\%).

\subsection{Statistical analysis}

Significant differences among the passion fruit samples were determined by one-way analysis of variance (Anova) using SPSS Program, version 14.0 (SPSS Inc., 2006). Principal component analysis (PCA) was applied using the same SPSS program. This technique was applied to the normalized peak areas from different chemical classes.

\section{Results and discussion}

Headspace SPME was used as a substitute of direct sampling mode since for volatile analytes, in the former mode, the equilibrium times are shorter compared to direct extraction. The headspace also protects the fibre from adverse effects caused by non-volatile, high molecular weight substances present in the sample matrix, and allows matrix modifications. A few key experimental factors which might influence the HSSPME extraction yield, namely time required for the target analytes to reach equilibrium and extraction temperature were optimised. Temperature has a significant effect on the extraction kinetics since it determines the vapour pressure of the analytes, and for this reason their influence in the extraction process was also investigated.

\subsection{Fibre selection}

The fibre coating is very important to define the optimum extraction conditions from the headspace. To evaluate the extraction yields of the passion fruit volatile components by HS-SPME, and taking account their physico/chemical characteristics, five types of fibres (CAR/PDMS, PDMS/DVB, PDMS, PA and StableFlex) with a range of polarities and mechanisms, among those used routinely for assaying volatiles, were tested. Each fibre was exposed to the headspace at the same temperature $\left(50{ }^{\circ} \mathrm{C}\right)$ during the same extraction time $(20 \mathrm{~min})$. All tests were carried out with the same passion fruit sample (purple passion fruit). The comparison of the SPME fibre performance was made in terms of extraction efficiency, estimated by the number of identifiable compounds in the extract and reproducibility. The chromatographic profiles, obtained for a purple passion fruit sample by using different coatings in the same experimental conditions, are presented in Fig. 1 indicating that PDMS/DVB fibre provided higher extraction efficiency to the volatiles. The results obtained using the five fibres on the same purple passion sample, in rigorously reproduced temperature and exposure time conditions, are reported in Table 1 . A total of seventy one volatile compounds, belonging to the carbonyl compounds, ethyl esters, higher alcohols, fatty acids and monoterpenoids, were tentatively identified by matching mass spectra with spectra of reference compounds in NIST mass spectral libraries with a resemblance percentage above $80 \%$. The Kováts retention indices (KI) were calculated for each peak and, when available, compared with the literature in order to certify the compound identification. The qualitative composition of passion fruit volatiles and the number of identified compounds using the five fibres under study are very different. As can be seen in Table 1 with PDMS/DVB fibre a total of 51 compounds were identified whilst with the StableFlex, CAR/PDMS, PDMS and PA coatings, were detected only, 45, 39, 31 and 28 compounds, respectively.

As shown in Fig. 2, where the total amounts obtained for each fibre are plotted, the semi-polar PDMS/DVB fibre allowed the best efficiency of extraction for volatile compounds, extracting around 1.1 times more than PA and StableFlex fibres and 1.3 times more than PDMS fibre. This fibre provided the best sensitivity in terms of total compound peak areas, highest number of detected compounds and high reproducibility, hence was chosen for screening the volatile compounds in passion fruits. CAR/ PDMS fibre coating extracted $60.6 \%$ of PDMS/DVB while PDMS coating extracted the lowest amount (about 51.6\%). Similar amounts of volatiles (73.8-88.1\%) were extracted when using either, PA or StableFlex coatings. Fig. 3 showed that fibres exhibited different selectivity to different target compounds. Ethyl esters (EE) have a larger affinity for PDMS/DVB fibre. This coating also presents a good sensitivity for higher alcohols (Alc) and C13-norisoprenoids/monoterpenes/sesquiterpenes (NMS). StableFlex was the fibre with most affinity for carbonyl compounds (CC).

Some characteristic passion fruit compounds were isolated by the five fibres: ethyl butanoate, ethyl hexanoate, hexyl acetate, (Z)-3hexenyl acetate, hexyl butanoate, ethyl octanoate, (Z)-3-hexenyl butanoate, cis- and trans-edulan I, linalool, $\beta$-ionone, (Z)-3-hexenyl hexanoate, benzyl acetate, phenylmethyl butanoate and phenylmethyl hexanoate.

\subsection{Extraction time and temperature}

Extraction time and temperature are important factors in SPME processes. Since time affects the mass transfer of the analytes onto the fibre, optimum time is required for the fibre to reach equilibrium with headspace. To study the effects of extraction time, purple passion fruit juice solutions were extracted for various periods ranging from 10 to $60 \mathrm{~min}$ at of $50{ }^{\circ} \mathrm{C}$. The results are shown in Fig. 4. It indicated that the peak areas increase with increasing extraction time in the range of 10 $40 \mathrm{~min}$ and reach their maximum value in $40-60 \mathrm{~min}$. When the time

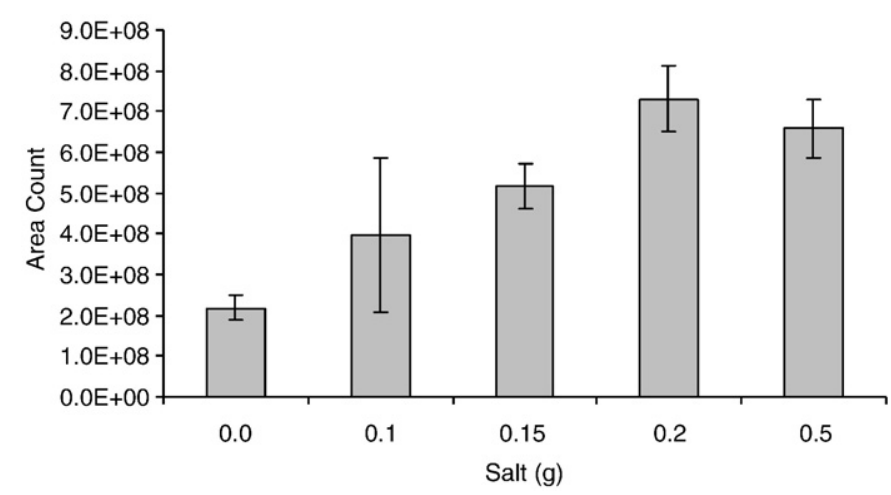

Fig. 6. Effect of salt addition ( $0.1,0.15,0.2$ and $0.5 \mathrm{~g} \mathrm{NaCl}, 1.2 \mathrm{ml}$ of sample) on the HSSPME extraction efficiency of purple passion fruit, using a PDMS/DVB fibre (40 min extraction time, $50{ }^{\circ} \mathrm{C}$ extraction temperature). 

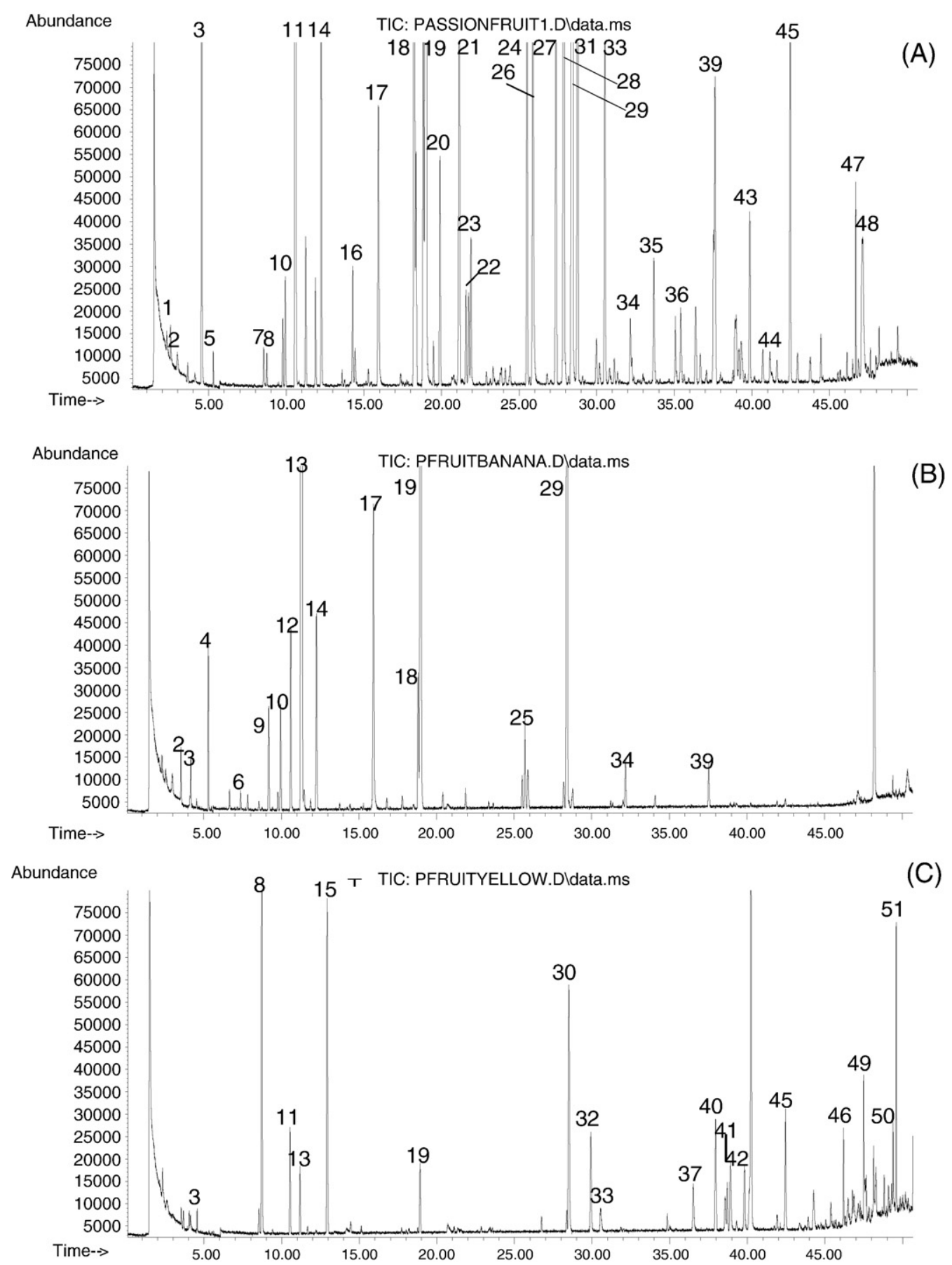

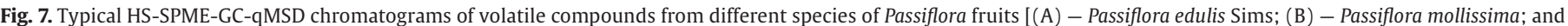
(C) - Passiflora edulis Sims f. flavicarpa] using: PDMS/DVB fibre at $50{ }^{\circ} \mathrm{C}, 40 \mathrm{~min}$, with $17 \% \mathrm{NaCl}(\mathrm{w} / \mathrm{v}$ ) and $750 \mathrm{rpm}$ (for peak identification see Table 2).

was further increased, no significant increase in the response was observed. For shorter analysis time $40 \mathrm{~min}$ of extraction time was selected.

Temperature is one of the most important experimental factors in SPME technique since it controls the diffusion rate of the analytes into the fibre. The extraction temperature was also determined and the results are shown in Fig. 5. Keeping the extraction time, the extraction temperature was carried out at five different temperatures from 40 to $80^{\circ} \mathrm{C}\left(40,50,60,70\right.$ and $\left.80^{\circ} \mathrm{C}\right)$ with a constant extraction time of $20 \mathrm{~min}$. On the basis of Fig. 5 , it can be found that the extracted amount increases with the extraction temperature. A temperature increase improves the mobility of volatile compounds through liquid and gas phases leading to an increase in extraction amounts. Despite the increasing extraction efficiency noted at high temperatures, $50{ }^{\circ} \mathrm{C}$ was chosen for further experiments. Temperatures as high as $80^{\circ} \mathrm{C}$ were discarded since high temperatures might cause thermal degradation of some compounds. So, the maximum extraction efficiency was obtained at $50{ }^{\circ} \mathrm{C}$ for extraction temperature and an exposure time of 40 min keeping the sample under constant agitation.

The effect of salt added to the samples has also been tested. For some analytes, unsalted solution is not significantly different from the same solution but with salt added. Fig. 6 showed that adding $\mathrm{NaCl}$ increased the extraction efficiency of the volatiles from passion fruit samples. 
Table 2

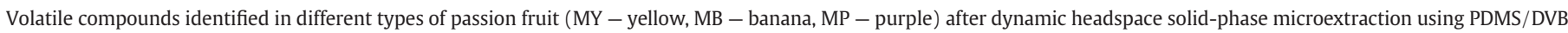
coating (extraction temperature: $50{ }^{\circ} \mathrm{C}$; extraction time: $40 \mathrm{~min} ; 750 \mathrm{rpm} ; 17 \% \mathrm{NaCl}, \mathrm{w} / \mathrm{v}$ ).

\begin{tabular}{|c|c|c|c|c|c|c|c|c|c|c|}
\hline \multirow[t]{2}{*}{ RT (min) } & \multirow[t]{2}{*}{ Peak No. } & \multirow[t]{2}{*}{$\mathrm{KI}^{\mathrm{a}}$} & \multirow[t]{2}{*}{$\mathrm{KI}^{\mathrm{b}}$} & \multirow[t]{2}{*}{ Compounds } & \multicolumn{3}{|l|}{ RPA (\%) } & $\mathrm{RPC}$ & & \\
\hline & & & & & $\overline{\mathrm{MY}}$ & MB & MP & $\overline{\mathrm{MY}}$ & $\mathrm{MB}$ & MP \\
\hline 2.539 & 1 & 907 & 907 & Ethyl acetate & - & - & 0.10 & - & - & 100 \\
\hline 3.536 & 2 & 984 & 991 & Pentan-2-one & 0.38 & 0.32 & - & 100 & 84 & - \\
\hline 3.670 & & 990 & 1001 & Methyl butanoate & 0.41 & - & 0.06 & 100 & - & 15 \\
\hline 4.039 & & & 1022 & 2-methyl methylbutanoate & 0.40 & 0.05 & 0.30 & 100 & 12 & 75 \\
\hline 4.540 & 3 & 1043 & 1048 & Ethyl butanoate & 0.46 & - & 3.26 & 14 & - & 100 \\
\hline 5.294 & 4 & 1075 & 1077 & Butyl acetate & - & 0.93 & - & - & 100 & - \\
\hline 5.298 & 5 & & 1082 & 1-methylpropyl acetate & - & - & 0.08 & - & - & 100 \\
\hline 7.380 & & 1143 & 1151 & Butan-1-ol & - & 0.12 & - & - & 100 & - \\
\hline 7.828 & 6 & 1145 & 1163 & B-myrcene & - & 0.09 & - & - & 100 & - \\
\hline 8.553 & 7 & 1170 & 1182 & Heptan-2-one & - & - & 0.12 & - & - & 100 \\
\hline 8.750 & 8 & 1188 & 1187 & Methyl hexanoate & 32.87 & - & 0.11 & 100 & - & 0.3 \\
\hline 9.181 & 9 & 1197 & 1196 & Eucalyptol & - & 0.83 & - & - & 100 & - \\
\hline 9.756 & & & 1209 & 1-methylbutyl butanoate & - & 0.13 & 0.22 & - & 59 & 100 \\
\hline 9.942 & 10 & & 1219 & Butyl butanoate & - & 0.78 & 0.37 & - & 100 & 47 \\
\hline 10.534 & 11 & 1238 & 1236 & Ethyl hexanoate & 3.19 & - & 9.31 & 34 & - & 100 \\
\hline 10.609 & 12 & 1242 & 1238 & $(E)$ - $\beta$-ocimene & - & 1.40 & - & - & 100 & - \\
\hline 11.187 & 13 & 1245 & 1254 & $(Z)$ - $\beta$-ocimene & 1.90 & 56.57 & 0.53 & 3 & 100 & 0.9 \\
\hline 11.787 & & & 1269 & 3-carene & - & 0.09 & - & - & 100 & - \\
\hline 11.865 & & & 1271 & 2-heptyl acetate & - & - & 0.39 & - & - & 100 \\
\hline 12.260 & 14 & 1274 & 1282 & Hexyl acetate & - & 0.56 & 1.92 & - & 29 & 100 \\
\hline 12.943 & 15 & & 1297 & (E)-methyl-2-hexenoate & 11.66 & - & - & 100 & - & - \\
\hline 13.574 & & & 1313 & Ethyl 4-hexenoate & - & - & 0.06 & - & - & 100 \\
\hline 14.220 & 16 & 1327 & 1328 & (Z)-3-hexen-1-yl acetate & - & - & 0.49 & - & - & 100 \\
\hline 14.437 & & 1320 & 1333 & Heptan-2-ol & - & - & 0.13 & - & - & 100 \\
\hline 15.287 & & & 1352 & Hexyl propanoate & - & - & 0.06 & - & - & 100 \\
\hline 15.925 & 17 & 1360 & 1366 & Hexan-1-ol & - & 3.05 & 1.31 & - & 43 & 100 \\
\hline 17.362 & & 1386 & 1395 & (Z)-3-hexen-1-ol & - & - & 0.04 & - & - & 100 \\
\hline 18.248 & & & 1417 & 1-methylhexyl butanoate & - & - & 3.89 & - & - & 100 \\
\hline 18.350 & & & 1420 & 2-methylbutyl hexanoate & - & - & 0.54 & - & - & 100 \\
\hline 18.827 & 18 & 1540 & 1432 & Butyl hexanoate & 0.11 & 1.00 & 1.87 & 6 & 54 & 100 \\
\hline 18.915 & 19 & 1533 & 1435 & Hexyl butanoate & 2.49 & 16.83 & 23.19 & 11 & 73 & 100 \\
\hline 19.490 & & & 1450 & 3-methylhexyl butanoate & - & - & 0.17 & - & - & 100 \\
\hline 19.899 & 20 & 1439 & 1460 & Ethyl octanoate & - & - & 0.99 & - & - & 100 \\
\hline 20.382 & & & 1472 & 3-methyl hexylbutanoate & - & 0.11 & - & - & 100 & - \\
\hline 21.144 & 21 & 1526 & 1491 & (Z)-3-hexenyl butanoate & - & - & 3.03 & - & - & 100 \\
\hline 21.582 & 22 & & 1501 & Trans-edulan i & - & - & 0.42 & - & - & 100 \\
\hline 21.752 & & & 1505 & Ethyl 4-octenoate & - & - & 0.34 & - & - & 100 \\
\hline 21.893 & 23 & 1497 & 1508 & Octyl butanoate & - & - & 0.64 & - & - & 100 \\
\hline 25.531 & 24 & 1551 & 1590 & Linalool & - & - & 1.93 & - & - & 100 \\
\hline 25.681 & 25 & & 1593 & Hexyl-2-butenoate & - & 0.89 & - & - & 100 & - \\
\hline 25.887 & 26 & 1553 & 1597 & Octan-1-ol & - & 0.33 & 2.74 & - & 12 & 100 \\
\hline 27.371 & 27 & & 1639 & 2-methyl propylhexanoate & - & - & 2.81 & - & - & 100 \\
\hline 27.881 & 28 & & 1653 & Cis-edulan i & - & - & 5.58 & - & - & 100 \\
\hline 28.420 & 29 & 1727 & 1668 & Hexyl hexanoate & 0.62 & 13.95 & 18.42 & 3 & 7 & 100 \\
\hline 28.495 & 30 & 1620 & 1670 & Methyl benzoate & 11.25 & - & - & 100 & - & - \\
\hline 28.767 & 31 & & 1677 & Decyl butanoate & - & - & 2.98 & - & - & 100 \\
\hline 29.927 & 32 & & 1709 & 3-hydroxymethyl hexanoate & 4.04 & - & - & 100 & - & - \\
\hline 29.983 & & & 1711 & (E)-3-octen-1-yl acetate & - & - & 0.19 & - & - & 100 \\
\hline 30.532 & 33 & 1729 & 1728 & (Z)-3-hexenyl hexanoate & - & - & 3.06 & - & - & 100 \\
\hline 32.153 & 34 & & 1775 & P-menth-1-en-8-ol & - & 0.39 & 0.24 & - & 100 & 62 \\
\hline 33.689 & 35 & 1829 & 1819 & Phenylmethyl acetate & - & - & 0.70 & - & - & 100 \\
\hline 35.417 & 36 & & 1868 & 2-hydroxymethyl benzoate & - & - & 0.39 & - & - & 100 \\
\hline 36.490 & 37 & & 1898 & 2-(2-butoxyethoxy)-ethanol & 1.59 & - & - & 100 & - & - \\
\hline 37.543 & 38 & & 1926 & Hexyl hexanoate & - & - & 0.72 & - & - & 100 \\
\hline 37.585 & 39 & 1806 & 1927 & Octyl octanoate & - & 0.38 & 1.53 & - & 25 & 100 \\
\hline 37.978 & 40 & 1952 & 1937 & $\alpha$-Ionone & 4.47 & - & - & 100 & - & - \\
\hline 38.713 & & & 1956 & Methyl dodecanoate & 1.50 & - & - & 100 & - & - \\
\hline 38.926 & 41 & 2060 & 1962 & Hexanoic acid & 3.12 & - & 0.28 & 100 & - & 9 \\
\hline 39.324 & & 1840 & 1972 & Geranyl acetone & - & - & 0.13 & - & - & 100 \\
\hline 39.821 & 42 & & 1984 & MHTP & 2.71 & - & - & 100 & - & - \\
\hline 39.857 & 43 & & 1985 & Phenylmethyl butanoate & - & - & 0.86 & - & - & 100 \\
\hline 41.152 & 44 & & 2125 & Linalyl acetate & - & - & 0.14 & - & - & 100 \\
\hline 42.459 & 45 & & 2170 & Dihydro $\beta$-ionone & 4.89 & - & 1.73 & 100 & - & 35 \\
\hline 46.182 & 46 & & 2289 & Isopropyl myristate & 2.14 & & - & 100 & - & - \\
\hline 46.698 & 47 & & 2301 & Phenylmethyl hexanoate & - & - & 0.51 & - & - & 100 \\
\hline 47.114 & 48 & & 2303 & 5-hydroxymethyl furfural & - & - & 1.16 & - & - & 100 \\
\hline 47.627 & & 2097 & 2306 & Ethyl cinamate & - & - & 0.07 & - & - & 100 \\
\hline 48.130 & 49 & 2202 & 2308 & Nonanoic acid & 1.06 & - & - & 100 & - & - \\
\hline 48.816 & & & 2312 & Methyl hexadecanoate & 0.64 & - & - & 100 & - & - \\
\hline 49.385 & 50 & & 2314 & $\mathrm{DDMP}^{\mathrm{d}}$ & 1.96 & - & 0.13 & 100 & - & 7 \\
\hline 49.591 & 51 & & 2315 & Methyl dihydrojasmonate & 6.17 & - & - & 100 & - & - \\
\hline Total comp & s identified & assion & & & & & & 24 & 21 & 51 \\
\hline Total area & & & & & $2.35 \mathrm{E}+07$ & $9.45 \mathrm{E}+07$ & $2.04 \mathrm{E}+08$ & & & \\
\hline$\% \operatorname{RSD}(n=$ & & & & & 0.17 & 0.51 & 5.58 & & & \\
\hline
\end{tabular}




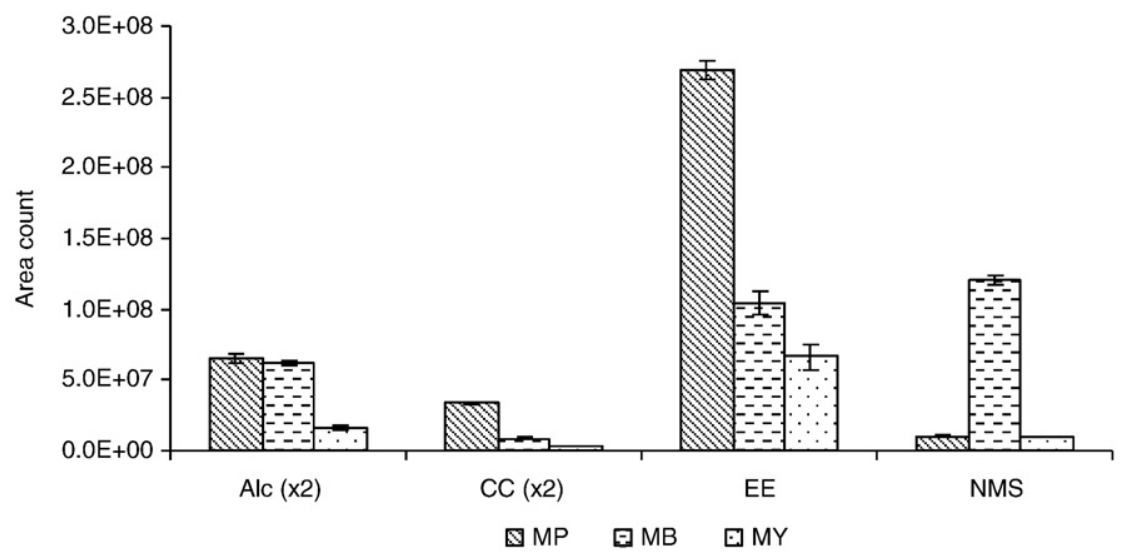

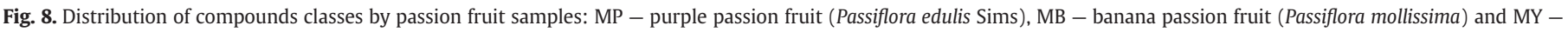

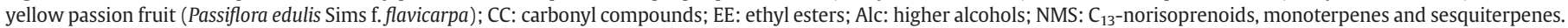

\subsection{Analysis of volatile compounds in passion fruit samples}

The proposed HS-SPME method, previously optimised and validated, was applied to investigate the volatile profile in different species of passion fruits. Each passion fruit sample was analysed four times using the best sampling conditions described above (i.e.: PDMS/ DVB fibre; $50{ }^{\circ} \mathrm{C}$ extraction temperature; 40 min extraction time; agitation at $750 \mathrm{rpm}$, salt addition: $\mathrm{NaCl},(17 \%,(\mathrm{w} / \mathrm{v})-0.2 \mathrm{~g}))$. This procedure allowed the detection of about seventy volatile compounds. A characteristic GC-qMS profile of each passion fruit species obtained with a PDMS/DVB fibre using the experimental optimised conditions is shown in Fig. 7. The identified compounds, described in Table 2, were organized in different groups according to their chemical structure, such as, monoterpenes $/ \mathrm{C}_{13}$-norisoprenoids (NMS), higher alcohols (Alc), ethyl esters (EE) and carbonyl compounds (CC). In average, ethyl esters, higher alcohols, carbonyl compounds and in less extension the monoterpenes $/ \mathrm{C}_{13}$-norisoprenoids, constituted a main part of the flavour of the studied passion fruit and they probably play a significant role in their organoleptic profile.

The volatile compounds were tentatively identified by matching mass spectra with spectra of reference compounds in NIST mass spectral library. In some cases a comparison with authentic compounds was performed. The Kováts retention indices were calculated for each peak and compared with the literature in order to ensure the correct identification of the compounds. Table 2 summarises the average $(n=4)$ relative composition in the studied passion fruits. The relative composition of each compound was calculated as the percent ratio of the respective peak area relative to the total peak area (RPA, \%) and relative to the compound with highest peak area in each passion fruit variety (RPC, \%).

Among the identified compounds, only 5 volatiles were simultaneously identified in all three samples: 2-methyl methylbutanoate, $(Z)-\beta$-ocimene, butyl hexanoate, hexyl butanoate and hexyl hexanoate (Table 2) with different relative contents. Some compounds identified in the different passion fruits like limonene, $\beta$-myrcene, $\beta$ ionone, 3-carene and others, have been reported as common components of various passion fruits [3,5].

The different species of passion fruit showed a typical composition (Fig. 7A; Table 2). Purple passion fruit (Fig. 7A) is characterised by a great number of identified compounds (51). The dominant compounds found in this variety of Passiflora fruits were hexyl butanoate (23.2\%), hexyl hexanoate (18.4\%), ethyl hexanoate (9.3\%), cis-edulan I (5.6\%), 1-methylhexyl butanoate (3.9\%), ethyl butanoate (3.3\%) and (Z)-3-hexenyl butanoate (3.0\%).

In banana passion fruit aroma, 22 volatile compounds were identified (Fig. 7B; Table 2). The biggest peaks correspond to $(Z)-\beta-$ ocimene (56.6\%), hexyl butanoate (16.8\%), hexyl hexanoate $(13.9 \%)$ and hexanol (3.1\%). Eight compounds - butyl acetate, butan-1-ol, $\beta$ myrcene, eucalyptol, (E)- $\beta$-ocimene, 3-carene, 3-methylhexyl butanoate, and hexyl-2-butenoate, have been detected only in this species with the same experimental conditions.

In yellow passion fruit (Fig. 7C; Table 2) 24 volatile compounds were detected and tentatively identified. The major compounds found in this variety were methyl hexanoate (32.9\%) followed by (E)-methyl-2hexenoate (11.7\%), methyl benzoate (11.3\%), methyl dihydrojasmonate (6.2\%), and dihydro $\beta$-ionone (4.9\%). This species presents fewer compounds than purple passion fruit. Some of the identified volatiles were found only in this species of passion fruit such as (E)-methyl-2hexenoate, methyl benzoate, 3-hydroxymethyl hexanoate, 2-(2-butoxyethoxy)ethanol, $\beta$-ionone, methyl dodecanoate, isopropyl miristate, ethyl cinnamate, isopropyl miristate, nonanoic acid, methyl hexadecanoate and methyl dihydrojasmonate. Fig. 8 presents the distribution of compounds classes by passion fruit sample.

\subsection{Principal component analysis}

The principal component analysis (PCA) was performed to study the main sources of variability between the passion fruit samples and detect the potential relationships/variables responsible for differentiation. The PCA led to the extraction of two principal components (eigenvalues $>1$ ) which contributed to $100.0 \%$ of the total variance of the data set (Table 3 ). The first principal component (PC1) identified as a linear combination of hexan-1-ol (1.000), butyl butanoate (0.997) and p-menth-1-en-8-ol (0.971) accounted for $64.41 \%$ of the variance. The second principal component ( $\mathrm{PC} 2$ ) was strongly characterized by octan-1-ol (1.000), penten-2-one (0.999), octyl octanoate (0.991) and hexyl acetate (0.984), and this factor contributed to $35.59 \%$ of the total

\footnotetext{
Notes to Table 2:

-: not detected.

a Kovàts retention indices from the literature.

b Experimentally determined Kovàts indices on the BP-20 column, relative to $C_{8}-C_{20}$ hydrocarbons.

c MHTP: 2-methyl-3-hydroxy-2,4,4-trimethylpentyl propanoate.

d DDMP: 2,3-dihydro-3,5-dihydroxy-6-methyl-4(H)-pyran-4-one.
} 
Table 3

Percentage of variance and percentage of cumulative variance explained by the four extracted principal components.

\begin{tabular}{|c|c|c|c|c|c|c|c|c|c|}
\hline \multicolumn{10}{|c|}{ Total variance explained } \\
\hline \multirow[t]{2}{*}{ Component } & \multicolumn{3}{|c|}{ Initial Eigenvalues } & \multicolumn{3}{|c|}{ Extraction sums of squared loadings } & \multicolumn{3}{|c|}{ Rotation sums of squared loadings } \\
\hline & Total & $\%$ of Variance & Cumulative $\%$ & Total & $\%$ of Variance & Cumulative $\%$ & Total & $\%$ of Variance & Cumulative $\%$ \\
\hline 1 & 13.527 & 64.412 & 64.412 & 13.527 & 64.412 & 64.412 & 10.832 & 51.580 & 51.580 \\
\hline 2 & 7.473 & 35.588 & 64.412 & 7.473 & 35.588 & 100.00 & 10.168 & 48.420 & 100.00 \\
\hline
\end{tabular}

Table 4

Loadings of volatiles in the first two principal components (1-PC1 and 2-PC2; rotation method: Varimax with Kaiser normalization; CC: carbonyl compounds; EE: ethyl esters; Alc: higher alcohols; NMS: norisoprenoids/monoterpenoids/sesquiterpenoids).

\begin{tabular}{|c|c|c|}
\hline \multicolumn{3}{|c|}{ Rotated component matrix ${ }^{\mathrm{a}}$} \\
\hline & \multicolumn{2}{|c|}{ Component } \\
\hline & 1 & 2 \\
\hline$\overline{\text { Zscore(c6oh) }}$ & 1.000 & .028 \\
\hline Zscore (c4c4) & .997 & .079 \\
\hline Zscore (mc4cl) & -.991 & .133 \\
\hline Zscore(menthene) & .971 & .239 \\
\hline Zscore(ionone) & -.962 & -.273 \\
\hline Zscore(Eocymene) & .915 & -.403 \\
\hline Zscore(Zocymene) & .906 & -.422 \\
\hline Zscore (mc4c) & -.879 & -.477 \\
\hline Zscore(c6ooh) & -.852 & -.524 \\
\hline Zscore(ddmp) & -.840 & -.542 \\
\hline Zscore(mc6) & -.808 & -.589 \\
\hline Zscore(c8oh) & .002 & 1.000 \\
\hline Zscore(pent2one) & -.038 & -.999 \\
\hline Zscore $(\mathrm{c} 8 \mathrm{c} 8)$ & .131 & .991 \\
\hline Zscore(c6acetate) & .178 & .984 \\
\hline Zscore $(c 4 c 2)$ & -.237 & .971 \\
\hline Zscore(c4c6) & .409 & .913 \\
\hline Zscore(c2c6) & -.438 & .899 \\
\hline Zscore(mbc4) & .496 & .868 \\
\hline Zscore(c6c4) & .592 & .806 \\
\hline Zscore (c6c6) & .640 & .768 \\
\hline
\end{tabular}

Extraction method: principal component analysis.

Rotation method: Varimax with Kaiser normalization.

a Rotation converged in 3 iterations.

variance. The scores scatter plot of PCA scores (Table 4) illustrated in Fig. $9 \mathrm{~A}$ and $\mathrm{B}$, demonstrate a clear separation between $P$. edulis Sims flavicarpa (MB), P. edulis Sims (MP) and P. mollissima (MY). This shows that the variables selected are able to explain the differences observed between groups.

\section{Conclusions}

The headspace solid-phase microextraction technique coupled with GC-qMS provides an appropriate and selective way to characterize the volatile compounds in different passion fruit species.

The chromatographic profiles obtained after extraction with PDMS, PA, CAR/PDMS, StableFlex and PDMS/DVB coatings suggest that the latter was the most suitable for the SPME analysis of passion fruit volatile organic compounds. The main volatile compounds identified in Passiflora fruits belong to the esters. The SPME procedure allowed the identification of 51 compounds in the P. edulis Sims, the prevailing compounds being: hexyl butanoate (23.2\%), hexyl hexanoate $(18.4 \%)$, ethyl hexanoate (9.3\%) followed by cis-edulan I (5.6\%). Only 24 volatile compounds were identified in the yellow passion fruit aroma, the most intense being methyl hexanoate $(32.9 \%)$ followed by (E)-methyl-2hexenoate (11.7\%) and methyl benzoate (11.3\%). In P. mollissima aroma the predominant volatiles were $(Z)-\alpha$-ocimene (56.6\%), hexyl butanoate $(16.8 \%)$ and hexyl hexanoate (13.9\%).

\section{References}

[1] K. Dhawan, S. Dhawan, A. Sharma, Passiflora: a review update, J. Ethnopharmacol. 94 (2004) 1-23.

[2] G. Tommoraro, C.S. Rodrigues, M. Santillana, B. Inmirzi, R. De Prisco, B. Nicolaus, A. Polti, J. Agric. Food Chem. 55 (2007) 7427.

[3] E. Carasek, J. Pawliszyn, Screening of tropical fruit volatile compounds using solidphase microextraction (SPME) fibres and internally cooled SPME fibre, J. Agric. Food Chem. 54 (2006) 8688-8696.

\section{Component Plot in Rotated Space}
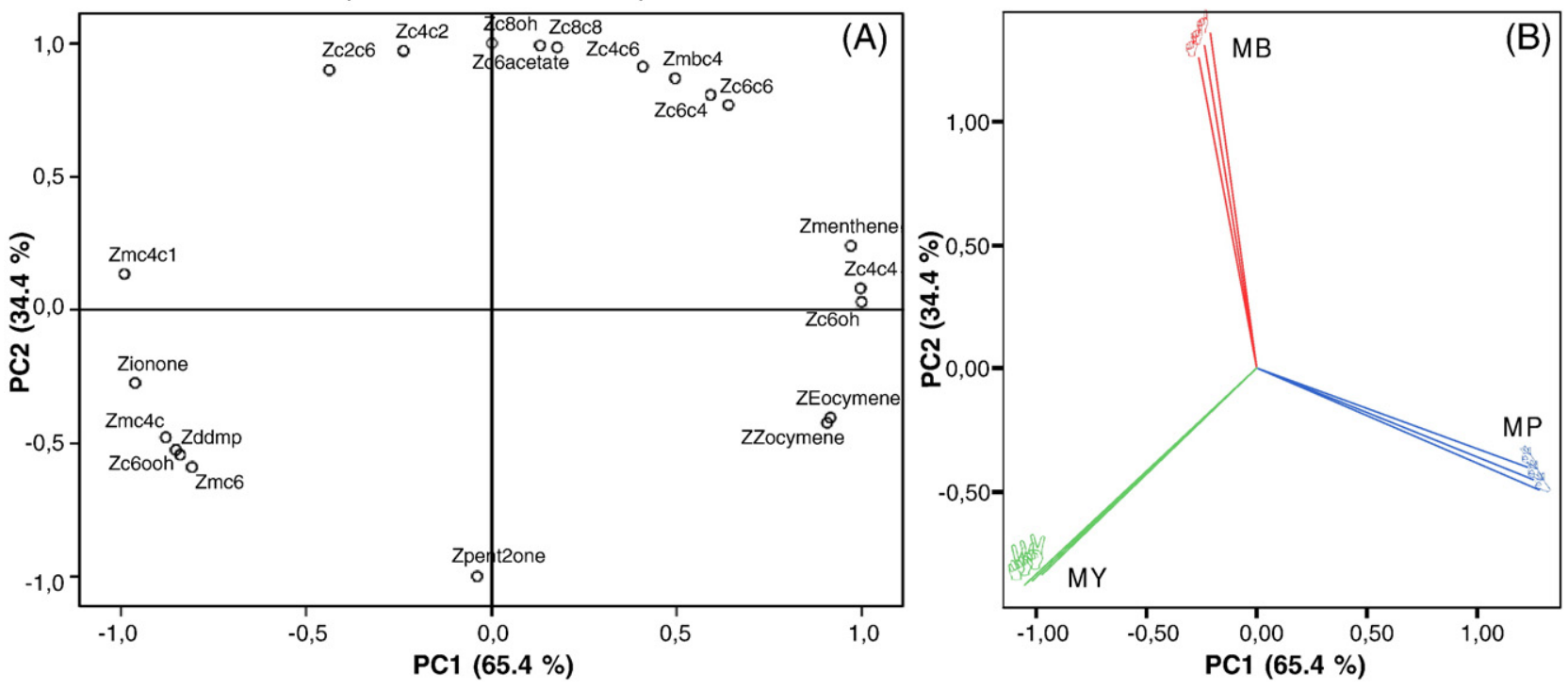

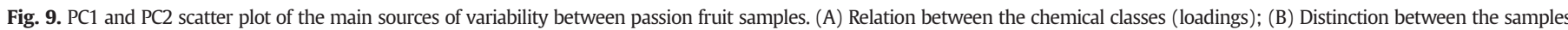

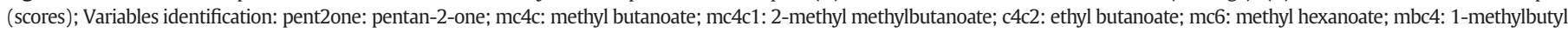

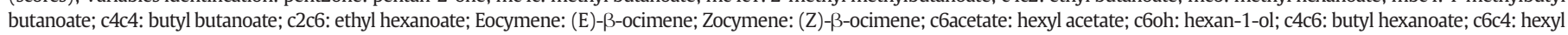
butanoate; c8oh: octan-1-ol; c6c6: hexyl hexanoate; menthene: p-menth-1-en-8-ol; c8c8: octyl octanoate; c6ooh: hexanoic acid; ionone: dihydro $\beta$-ionone; ddmp: DDMP. 
[4] R.A. Pérez, C. Sánchez-Brunete, R.M. Calvo, J.L. Tadeo, Analysis of volatiles from Spanish honeys by solid-phase microextraction and gas chromatography-mass spectrometry, J. Agric. Food Chem. 50 (2002) 2633-2637.

[5] M. Riu-Aumatell, M. Castellari, E. López-Tamames, S. Galassi, S. Buxaderas, Characterisation of volatile compounds of fruit juices and nectars by HS/SPME and GC/MS, Food Chem. 87 (2004) 627-637.

[6] J.S. Pruthi, G. Lal, Chemical composition of passion fruit (Passiflora edulis, Sims.), J. Sci. Food Agric. 10 (2006) 188-192.

[7] S. Zibadi, R.R. Watson, Passion fruit (Passiflora edulis): composition, efficacy and safety. review article, Evid. Based Integr. Med. 1 (2004) 183-187.

[8] S.T. Talcott, S.S. Percival, Y. Pittet-Moore, C. Celoria, Phytochemical composition and antioxidant stability of fortified yellow passion fruit (Passiflora edulis), J. Agric Food Chem. 51 (2003) 935-941.

[9] P. Werkhoff, M. Güntert, G. Krammer, H. Sommer, J. Kaulen, Vacuum headspace method in aroma research: flavor chemistry of yellow passion fruits, J. Agric. Food Chem. 46 (1998) 1076-1093.

[10] D. Sandi, J.B.P. Chaves, A.C.G. Sousa, J.F.M. Parreiras, M.T.C. Silva, P.B.L. Constant Hunter color dimensions, sugar content and volatile compounds in pasteurized yellow passion fruit juice (Passiflora edulis var. flavicarpa) during storage, Brazil. Arch. Biol. Technol. 47 (2004) 233-245.

[11] S. Rocha, V. Ramalheira, A. Barros, I. Delgadilho, M.A. Coimbra, Headspace solid phase microextraction (SPME) analysis of flavor compounds in wines. Effect of the matrix volatile composition in the relative response factors in a wine model, J. Agric. Food Chem. 49 (2001) 5142-5151.

[12] C. Pizarro, N. Pérez-del-Notario, J.M. González-Sáiz, Multiple headspace solid-phase microextraction for eliminating matrix effect in the simultaneous determination of haloanisoles and volatile phenols in wines, J. Chromatogr. A 1166 (2007) 1-8.

[13] J.D. Carrillo, C. Salazar, C. Moreta, M.T. Tena, Determination of phthalates in wine by headspace solid-phase microextraction followed by gas chromatography-mas spectrometry: fibre comparison and selection, J. Chromatogr. A 1164 (2007) 248-261.

[14] B. Fedrizzi, G. Versini, I. Lavagnini, G. Nicolini, F. Magno, Gas chromatography-mass spectrometry determination of 3-mercaptohexan-1-ol and 3-mercaptohexyl acetate in wine A comparison of headspace solid phase microextraction and solid phase extraction methods, Anal. Chim. Acta 596 (2007) 291-297.

[15] R. Perestrelo, M. Caldeira, F. Rodrigues, J.S. Câmara, Volatile flavour constituent patterns of Terras madeirenses red wines extracted by dynamic headspace solidphase microextraction, J. Sep. Sci. 31 (2008) 1841-1850.

[16] J.S. Câmara, M. Arminda Alves, J.C. Marques, Development of headspace solidphase microextraction-gas chromatography-mass spectrometry methodology fo analysis of terpenoids in Madeira wines, Anal. Chim. Acta 555 (2006) 191-200.
[17] F. Rodrigues, M. Caldeira, J.S. Câmara, Development of a dynamic headspace solidphase microextraction procedure coupled to GC-qMSD for evaluation the chemical profile in alcoholic beverages, Anal. Chim. Acta 609 (2008) 82-104.

[18] Q. Xiao, C. Yu, J. Xing, B. Hu, Comparison of headspace and direct single-drop microextraction and headspace solid-phase microextraction for the measurement of volatile sulfur compounds in beer and beverage by gas chromatography with flame photometric detection, J. Chromatogr. A 1125 (2006) 133-137.

[19] O. Pinho, I.M.PLV.O. Ferreira, LH.M. Method optimization by solid-phase microextraction in combination with gas chromatography with mass spectrometry for analysis of beer volatile fraction, J. Chromatogr. A 1121 (2006) 145-153.

[20] J.S. Câmara, J.C. Marques, R.M. Perestrelo, F. Rodrigues, L. Oliveira, P. Andrade, M. Caldeira, Comparative study of the whisky aroma profile based on headspace solid phase microextraction using different fibre coatings, J. Chromatogr. A 1150 (2007) 198-207.

[21] J.C.R. Demyttenaer, J.I.S. Martínez, R. Verhé, P. Sandra, R. De Kimpe, Analysis of volatiles of malt whisky by solid-phase microextraction and stir bar sorptive extraction, J. Chromatogr. A 985 (2003) 221-232.

[22] L.F. Cuevas-Glory, J.A. Pino, L.S. Santiago, E. Sauri-Duch, A review of volatile analytical methods for determining the botanical origin of honey, Food Chem. 103 (2007) 1032-1043.

[23] M. Pontes, J.C. Marques, J.S. Câmara, Screening of volatile composition from Portuguese multifloral honeys using headspace solid-phase microextraction-gas chromatography-quadrupole mass spectrometry, Talanta 74 (2007) 91-103.

[24] F. Bianchi, C. Cantoni, M. Careri, L. Chiesa, M. Musci, A. Pina, Characterization of the aromatic profile for the authentication and differentiation of typical Italian drysausages, Talanta 72 (2007) 1552-1563.

[25] D.D. Roberts, P. Pollien, C. Milo, Analysis of volatiles from Spanish honeys, J. Agric. Food Chem. 48 (2000) 2430-2437.

[26] X. Yang, T. Peppard, Solid-phase microextraction for flavor analysis, J. Agric. Food Chem. 42 (1994) 1925-1930.

[27] L. Ferreira, R. Perestrelo, J.S. Câmara, Comparative analysis of the volatile fraction from Annona cherimola Mill. cultivars by solid-phase microextraction and gas chromatography-quadrupole mass spectrometry detection, Talanta 77 (2009) 1087-1096.

[28] T.T. Liu, T.S. Yang, Optimization of solid-phase microextraction analysis for studying change of headspace flavor compounds of banana during ripening, J. Agric. Food Chem. 50 (2002) 653-657.

[29] X.M. Wan, R.Y. Stevenson, X.D. Chen, L.D. Melton, Application of headspace solidphase microextraction to volatile flavour profile development during storage and ripening of kiwifruit, Food Res. Int. 32 (1999) 175-183. 